\title{
Do the Causal Effects of Internal Collaboration and Extemal Collaboration Improve Performance in Supply Chains?
}

\author{
Hee-sung Bae*, Yang-kee Lee**
}

\begin{abstract}
There are three aims of this research. One is to verify the mutual effects between internal collaboration and external collaboration, another is to prove performance improvement among different levels of supply chain collaboration, and the third is to analyze gaps between the two viewpoints. The population is Korean FDI firms in China and 208 data are used in the analysis. The data are treated with various methods: exploratory and confirmatory factor analyses, SEM, cluster analysis, ANOVA, MANOVA and post hoc analysis. The results are as follows. First, external collaboration and internal collaboration have positive effects on each other, which have a positive effect on performance. This means that efficiency of internal processes is the cause of promoting connection with external processes and information generated from the market is the basis of a variance of internal processes, followed by high performance. Second, service performance improvement is more definite than cost performance improvement among different levels of supply chain collaboration. Firms can achieve more definite results in service performance when they perform supply chain collaboration. Third, this research verifies both the viewpoint of directions of supply chain collaboration and the strategic choice viewpoint of supply chain collaboration to better understand supply chain collaboration. Both viewpoints approach supply chain collaboration from different viewpoints but they do explain the methods for performance improvement.
\end{abstract}

Key Word: Supply Chain, Collaboration, Performance, FDI firms

JEL classification: F23 \& M16

\footnotetext{
* First Author, Pusan National University, Busan City, Republic of Korea

Email: h.s.bae@pusan.ac.kr

** Corresponding Author, Pusan National University, Busan City, Republic of Korea Email: yangkee21@pusan.ac.kr
} 


\section{Introduction}

Supply chain collaboration (SCC) is an important strategic consideration for foreign direct investment (FDI) firms, which need to effectively manage the globalization of the value chains of manufacturing firms. Traditional FDI theory focuses on explaining multinational enterprises' FDI motives in terms of resource-seeking, market-seeking and efficiency-seeking (Buckley and Casson, 1976; Hennart, 1982; Rugman, 1981). The FDI theory also explains the entry modes into the foreign market and the strategic behavior of FDI firms. However, these explanations have limitations because they are not able to explain how FDI firms manage their SCC after entering the foreign market.

From the viewpoint of FDI, China is not to be overlooked because they are the world's factory. For this reason, many firms have performed FDI into China, and, equally so, many Korean firms have carried out FDI in China. Korean firms have invested US\$31.6 billion and about 21,400 firms have set themselves up in China as at the end of 2010 (US\$2.2 billion and about 650 firms in 2010) (Korea Export and Import Bank, 2011). International business studies show that China plays an important role for the success of FDI firms, which allows them to procure low costs of components, save production costs and extend their market. Like other FDI firms, Korean FDI firms in China have to structure a whole new value creation network. Among others, prior literature has suggested that SCC could create value and superior performance in a supply chain and perhaps also in such as a newly created supply network. In particular, FDI firms could analyze SCC strategies in order to maximize the potential of the FDI venture. While the consideration of FDI firms into the research on SCC is rather new, there are still many unanswered questions.

The prior research on SCC and its performance can be divided into three perspectives: internal collaboration (IC) (Gimenez and Ventura, 2005; Daugherty et al., 2009), external collaboration (EC) (Bagchi et al., 2005; Chen et al., 2009) and SCC as a whole (Bae, 2014; Boon-itt and Wong, 2011a, b; Iyer, 2011). Most studies verify that these collaboration constructs have a positive effect on performance. In addition, IC is found to have a positive effect on EC (Gimenez, 2006; Chen et al., 2009) and vice versa (Bae, 2012; Stank et al., 2001). This is based on the work of Stevens (1989) and is explained as the viewpoint of the flow of SCC. On the other hand, some researchers insisted that different levels of SCC have different performance (Frohlich and Westbrook, 2001; Flynn et al., 2010; Schoenherr and Swink, 2012). In other words, this means that there is performance improvement among different levels of SCC (Bae, 2012). This can be explained as the strategic choice viewpoint of SCC at the present time. These contrary viewpoints remain an unresolved research gap.

From the above viewpoints, prior research has three limitations. First, the relationship 
between IC and EC is indefinite. Some researchers have verified that IC has a positive influence on EC (Braunscheidel and Suresh, 2009; Chen et al., 2009; Gimenez and Ventura, 2005; Gimenez, 2006; Schoenherr and Swink, 2012). On the other hand, others have proved that EC has a positive influence on IC (Bae, 2012; Gimenez and Ventura, 2005; Salvador et al., 2001; Stank et al., 2001). In addition, there is another research which did not find any effect (Gimenez and Ventura, 2005; Gimenez, 2006). Therefore, this research needs to ascertain the mutual effect between IC and EC and the effect of them on performance. Second, research on performance improvement among different levels of SCC was analyzed from various viewpoints. However, prior research has limitations such as complexity in the contents of SCC (Bae, 2014; Flynn et al., 2010; Frohlich and Westbrook, 2001; Morash and Clinton, 1998; Schoenherr and Swink, 2012; Thun, 2010) and the unclear effect of SCC on performance (Narasimhan and Kim, 2001, 2002; Stock et al., 2000). In this regard, this research needs to ascertain performance improvement among different levels of SCC. Third, almost prior research has been performed in the perspective of development stages of SCC (Stevens, 1989; Schoenherr and Swink, 2012). It has a precondition that SCC is developed from IC to EC. However, this research explains two different viewpoints; that is, one is the viewpoint on directions of SCC and the other is the strategic choice viewpoint on levels of SCC. For this reason, the analyses on the two viewpoints can help to better understand SCC. Therefore, this research will verify the directions of SCC and performance improvement among different levels of SCC from the viewpoint of Korean FDI firms in China.

\section{Literature Review}

\subsection{The Effect of EC on IC}

The relationship between IC and EC can be explained by contingency theory and information processing theory. The former means that firms can minimize the effect of environment on performance through changing internal environment caused by variation of external environment and, from the viewpoint, suppliers and customers are regarded as external environment and have an effect on performance (Flynn et al., 2010). In addition, the latter explains that environment reflects all factors to exist outside of firms and the market can be treated as a part of environment. Information acquired from the market is learned by managers, disseminated to all departments and applied to firms through proper processing. As a result, firms improve processes and solve problems, followed by improved 
performance (Tuggle and Gerwin, 1980). From the viewpoints, EC is the basis of IC. Prior research has verified that EC has a positive effect on IC (Gimenez and Ventura, 2005; Salvador et al., 2001; Stank et al., 2001).

External environment is the root of information and firms grasp customer needs through information collected from environment and change internal processes to achieve the needs. This is similar with the flow of information which comes from market orientation (Kohli and Jaworski, 1990). Information generated from customers leads to a variation of internal processes and firms can structure collaborative supply chains because the information is shared with suppliers. The supply chain processes are connected with high performance. Stank et al. (2001) insisted that information generated from the exterior is the cause of efficient processes because it is put in the interior. This stresses the importance of the flow of information as well as the importance of external information. Firms collaborate with customers and suppliers to acquire information and, as a result, acquired information is shared with all departments. In addition, variation of processes has a positive effect on cost saving because of removing overlaps and inefficiencies existing in the processes. All departments can recognize customer needs through information sharing and this is connected with high customer service. This can be explained by fit as mediation of Venkatraman (1989). This means that IC mediates the relationship between EC and performance. Therefore, this research proposes a hypothesis as follows.

$<$ H. 1> Customer collaboration (H. 1a) and supplier collaboration (H. 1b) have a positive effect on internal collaboration, which has a positive effect on cost performance (H. 1c) and service performance (H. 1d).

\subsection{The Effect of IC on EC}

From the viewpoint of information processing theory, improved internal processes are the cause of construction of effective relationships with suppliers and customers. If each firm has standardized information processing capability, they better share information and, consequently, enjoy high performance through the relationships. Similarly, from the viewpoint of resource-based theory, IC is regarded as an internal resource of firms. The resource has four characteristics such as usefulness, rareness, imperfect imitation and non-substitution (Barney, 1991). IC can be a core competence because of characters such as difficulty of imitation by competitors and leverage to the other business units. This competence is combined with the competence of partners like suppliers and customers through SCC and this is connected with high performance. In this regard, IC is the basis of 
EC. Prior research has proved that IC has a positive effect on EC (Braunscheidel and Suresh, 2009; Chen et al., 2009; Gimenez and Ventura, 2005; Gimenez, 2006; Schoenherr and Swink, 2012).

Efficient internal processes enhance the capability to respond to information and opportunities generated from the exterior. From the viewpoint of knowledge management, the capability is shared with partners and this is connected with high performance. From the viewpoint of manufacturing firms, the construction of standardized processes enhances standardization of works among customers and suppliers and costs are saved by the standardization. In addition, they can provide partners with useful information through efficient information sharing. They structure efficient internal processes to accord with customer requirements through sharing customer information with all departments first, and then they can make efficient supply chain processes to achieve customer needs through sharing the information with suppliers. Therefore, firms can achieve whole efficiency if they make efficient internal processes first and then connect the processes with partners who possess efficient internal processes. Firms which have the efficient supply chains can achieve high performance through improving service and saving costs. This can be explained by fit as mediation of Venkatraman (1989). This means that EC mediates the relationship between IC and performance. Therefore, this research proposes a hypothesis as follows.

$<$ H. 2> Internal collaboration has a positive effect on customer collaboration (H. 2a) and supplier collaboration (H. 2b), which have a positive effect on cost performance (H. 2c) and service performance (H. 2d).

\subsection{Cost Performance Improvement among Different Levels of SCC}

SCC starts from IC and develops to EC (Stevens, 1989). However, the relationship between IC and EC is still controversial. Some researchers have found that IC has a positive influence on EC (Braunscheidel and Suresh, 2009; Chen et al., 2009: Gimenez, 2006; Schoenherr and Swink, 2012) and others have verified that EC has a positive influence on IC (Bae, 2012; Salvador et al., 2001; Stank et al., 2001). In addition, there is research which ascertained the positive effect of interaction between IC and EC on performance (Boon-itt and Wong, 2011b; Droge et al., 2004; Germain and Iyer, 2006) and research which confirmed the positive effect of interaction between customer collaboration and supplier collaboration on performance (Danese and Romano, 2011; Flynn et al., 2010). The flow of the research explains the relationship between IC and EC. 
The major perspective on SCC which has been shown in prior research is that firms achieve IC and perform EC on the basis of the IC. Gimenez (2006) insisted that external integration is a phenomenon shown as a result of IC and, in this regard, firms should achieve IC first to enhance EC. The relationship between IC and EC can be explained by information processing theory. Managers grasp customer needs through learning information about the exterior and improve internal processes to fit the information. Improved internal processes are the cause of performing effective collaboration with suppliers and customers. As a result, firms achieve efficiency in internal processes and effectiveness in external processes, followed by superior performance. The perspective of the flow on development stages of SCC approaches IC and EC to the concept of sequence. However, from the viewpoint of strategic choice theory, firms can choose IC, EC or SCC on the basis of managers' cognition of environment, position in the market, present processes and internal resources. The choice of firms on levels of SCC from the strategic viewpoint is directly connected with performance outcomes. In particular, firms ascertain their level of SCC at the present time and, as a result, they can find developing possibility of their level of SCC for performance improvement. This viewpoint can be explained by strategic choice theory.

Prior research confirmed gaps in performance among different levels of SCC. Daugherty et al. (1996) proved that integrated firms have better performance such as improved customer service, quality improvements, productivity improvements, reduced costs, improved strategic focus and cycle time reductions compared with non-integrated firms. Flynn et al. (2010) verified that there is a gap in organizational performance and business performance among supply chain integration patterns. These results explain that the larger the supply chain integration strength, the better the organizational performance and business performance. This means that if firms achieve SCC from the viewpoint of IC and EC, they can create superior performance. In addition, Frohlich and Westbrook (2001) have confirmed that supplier and customer integration has the highest performance improvement and this also explains that the higher the integration, the higher the performance. These results support that a strategic choice of firms on different levels of $\mathrm{SCC}$ is the cause of gaps in performance.

It is important to achieve EC by connecting with suppliers and customers as well as achieving IC within a firm. SCC is thought to begin with an internal aspect of a firm, and then developed into the relationships between partners and, finally, along these stages contribute more to service effectiveness and cost efficiency. For this reason, different levels of SCC for FDI firms can be explained by two elements: one is to structure internal systems through IC and the other is to build up relationships with supply chain partners through EC, which connects inter-firm systems. Firms, through SCC, attain cost advantages such as cost 
savings following the efficient use of resources, lower waste by reducing overlaps of resources, proper replacement of resources and improved efficiency of processes. The results of prior research support this explanation. Researchers confirmed that the higher the level of SCC, the higher the cost performance (Daugherty et al., 1996; Flynn et al., 2010; $\mathrm{Kim}, 2006)$. Therefore, this research proposes a hypothesis as follows.

$<$ H.3 $>$ FDI firms with higher levels of supply chain collaboration (internal and external collaboration) achieve better cost performance than FDI firms with lower levels of supply chain collaboration.

\subsection{Service Performance Improvement among Different Levels of SCC}

The theoretical relationship between levels of SCC and performance was already explained in H.3 as above. The relationship between different levels of SCC and service performance is as follows. SCC should include decision-making among firms and joint responsibility as the result of the process of decision-making between supply chain partners. Managers should make an effort to form a collaborative spirit among supply chain partners as well as departments by making a cooperative effort in common activities and they should achieve joint goals through SCC. If they make consistency between the goals of a department or a firm and supply chain goals, they can achieve overall goals by adjusting inefficient processes, and thus adding value to the supply chain process (Stank et al., 2001). In addition, firms which collaborate with customers are more likely to provide high quality services because of the ability of the collaborative efforts, which help to attain joint goals, and to support information sharing for rapid and accurate responses to customer needs. Thus, these firms can provide service differentiation compared with competitors in the market. Some prior studies found that firms enjoy high service performance when they attain a high level of SCC (Daugherty et al., 1996; Kannan and Tan, 2010; Saeed et al., 2011; Thun, 2010). These results reflect service performance improvement vary according to the levels of SCC. Therefore, this research suggests a hypothesis as follows.

$<$ H.4> FDI firms with higher levels of supply chain collaboration (internal and external collaboration) achieve better service performance than FDI firms with lower levels of supply chain collaboration. 


\section{Research Methods}

\subsection{Definitions of Variables}

SCC can be defined as working together among departments within a firm, understanding each other's different viewpoints, sharing resources and information and achieving common goals in supply chains (Kahn and Mentzer, 1998). IC can be defined as processes of cooperation and interaction for maintenance of the close relationship between departments. On the other hand, EC can be also defined as the operational cooperation and interaction of the relationships between firms in supply chain contexts, which can be classified into supplier collaboration and customer collaboration (Ellinger et al., 2000; Kahn and Mentzer, 1998; Mollenkopf et al., 2000). Supplier collaboration means structuring collaborative relationships with core suppliers for stock management and stable supply of raw materials and parts and customer collaboration means understanding the needs of core customers and response to the understanding (Thun, 2010). Customer collaboration is measured as close contact with customers concerned with goods and services (SCC 1), rapidness of order processes (SCC 2), a high level of information sharing with customers (SCC 3), smooth communication with customers concerned with goods and services (SCC 4) and supplying goods and services to respond to customer needs (SCC 5). Supplier collaboration is measured as an exchange of harmonized information with suppliers (SCC 6), participation of suppliers in inventory control (SCC 7), use of quick response (SCC 8), a degree of network integration with suppliers for stable purchase (SCC 9) and a degree of receiving stable goods and services from suppliers (SCC 10). IC is measured as the possibility of real time checking of data concerned with goods and services (SCC 11), sharing information among departments (SCC 12), a degree of integrated inventory control (SCC 13), the possibility of real time checking on total stock (SCC14) and a high level of information integration in production processes (SCC 15). All items are measured as perceptions on a seven Likert scale.

Operational performance can be measured in terms of efficiency and effectiveness. The former is a degree of economically using internal resources of firms and the latter means a degree of achieving the goals of firms (Chow et al., 1995). In this regard, operational performance is measured as cost performance from the viewpoint of efficiency and service performance from the viewpoint of effectiveness in this research (Brewer and Speh, 2000). Cost performance is measured as a degree of saving of labor costs following reduction and re-disposition of workers (CP 1), a degree of cost saving concerned with decreasing stock (CP 2), a degree of cost saving concerned with stock management (CP 3), 
a degree of cost saving concerned with order management (CP 4) and a degree of cost saving concerned with contact with partners (CP 5). Service performance is measured as a degree of increased flexibility of operations through cooperation with partners (SP 6), ability to fulfill special requirements of customers (SP 7), ability to supply estimated quantity on time (SP 8), ability to provide customers with value added service (SP 9) and ability to cooperatively overcome any problems with partners if they occur (SP 10). All items are measured as perceptions on a seven Likert scale.

\subsection{Data Collection and Analytical Methods}

The population of this research is Korean FDI firms in China because many Korean firms have carried out direct investment in China. Many Korean FDI firms are manufacturing in China and selling products produced from there to the world market. Therefore, it is important to ascertain whether the Korean FDI firms in China carry out SCC, which is regarded as reflecting very well the goals of this research. Sample frame means a membership list to stand for a population which is the object of this research. In this research, the sample frame can be shown by a Chinese membership list of Korea International Trade Association. They are selected for two reasons: one is that almost all Korean manufacturing firms in China are members of the association and the other is that service firms such as hotels, tourist agencies and personal service firms are not the object of this research. Random sampling was used in this research. A questionnaire was sent to staff of marketing departments or logistics departments of the sample firms because they perform the work concerned with supply chain management $(\mathrm{SCM})$ in business practice and, in addition, they have a good deal of knowledge concerned with SCC. Almost all questionnaires were collected by personal visits and Korean students of Renmin University in China helped to collect data for the survey. Respondents were also allowed to answer the questionnaire using facsimile, telephone or email if they wanted to.

Various analytical methods are used to analyze collected data. First, reliability and validity are tested by Cronbach's alpha, correlation analysis, exploratory factor analysis and confirmatory factor analysis. If a Cronbach's alpha coefficient is over 0.6 and the average variance extracted (AVE) is over 0.5 , there is no problem with reliability (Nunnally, 1978). In addition, if the AVE is larger than the squared correlation coefficients, there is no problem in discriminant validity. Correlation analysis has two aims: one is that independent variables explain dependent variables well if there are high correlation coefficients between the former and the latter and the other is that multicollinearity is doubted if there are high correlations between independent variables. Exploratory factor analysis is used to verify 
whether measuring items explain the variable. There are three criteria: one is over 0.5 in a factor loading coefficient, another is factor cross loading, and the third is over 1.0 in eigenvalue. In addition, the criterion of Bartlett test is below 0.05 in $\mathrm{p}$ value and the criterion of KMO (Kaiser-Meyer-Olkin) is over 0.5. Confirmatory factor analysis is to ascertain fit of measuring items. The criteria are over 0.5 in the AVE, below 2.0 in Q (chi-square/degree of freedom), over 0.9 in GFI, AGFI and CFI and below 0.08 in RMSEA. Second, causal links between IC and EC are verified by analyzing structural equation modeling (SEM). SEM is useful to test causal links among variables. In particular, it can be usefully used in path analysis. One of the aims of this research is to prove whether IC has a positive effect on performance by way of EC and whether EC has a positive effect on performance by way of IC. Therefore, SEM is the most proper method. Third, performance improvement among different levels of SCC is verified by cluster analysis, analysis of variance (ANOVA), multivariate analysis of variance (MANOVA) and post hoc analysis. Cluster analysis is used in classifying levels of SCC on the basis of IC and EC. ANOVA is used in confirming independence among the classified clusters. MANOVA is used in proving gaps in performance among the clusters. However, the limitation of MANOVA is that the result does not show real gaps in performance among clusters. Therefore, post hoc analysis using Scheffe test is used to verifying it.

\section{The Results of the Empirical Tests}

\subsection{General Characteristics of the Responding Firms}

Before testing hypotheses, this research investigates general characteristics of the responding firms. The results are as follows.

Table 1.

General Characteristics of the Responding Firms

\begin{tabular}{l|c|l|c}
\hline \multicolumn{1}{c|}{ Type of business } & n (\%) & Annual turnover (U\$ a million) & n (\%) \\
\hline Chemistry/ rubber & $12(5.8)$ & Below 1 & $41(19.7)$ \\
Electronics/electricity & $48(23.1)$ & $1-5$ & $78(37.5)$ \\
Metal/nonmetal & $51(24.5)$ & $5-10$ & $15(7.2)$ \\
Machine/transport/equipment & $14(6.7)$ & $10-100$ & $24(11.5)$ \\
Fiber/clothing/leather & $50(24.0)$ & Over 100 & $6(2.9)$ \\
Lumber/paper/furniture & $8(3.8)$ & No answer & $44(21.2)$ \\
\hline
\end{tabular}




\begin{tabular}{|c|c|c|c|}
\hline Type of business & n (\%) & Annual turnover (US a million) & n (\%) \\
\hline \multirow{5}{*}{$\begin{array}{l}\text { Food/beverage } \\
\text { Others } \\
\text { No answer }\end{array}$} & \multirow{5}{*}{$\begin{array}{l}12(5.8) \\
8(3.8) \\
5(2.4)\end{array}$} & The number of employees & $\mathrm{n}(\%)$ \\
\hline & & Below 100 & $85(40.9)$ \\
\hline & & $100-500$ & $68(32.7)$ \\
\hline & & Over 500 & $37(17.8)$ \\
\hline & & No answer & $18(8.6)$ \\
\hline Total & $208(100)$ & & \\
\hline
\end{tabular}

As shown in $<$ Table 1 $>$, metal and nonmetal have the largest number of firms which is $51(24.5 \%)$ and lumber, paper and furniture have the smallest firms which is $8(3.8 \%)$. Responding firms are variously distributed in the types of business and this means that sample firms are not biased. Annual turnover of responding firms shows that there are 119 firms (57.2\%) below U\$ 5 million and this means that many Korean FDI firms in China are small and medium size enterprises (SMEs). Similarly, the number of employees also explains that 85 firms (40.9\%) are below 100 and this also means that they are SEMs.

\subsection{Reliability and Validity Tests}

Before testing hypotheses, this research proves reliability and validity on collected data. The results are as follows.

Table 2.

Factor Analysis Results

\begin{tabular}{|c|c|c|c|c|c|c|}
\hline \multirow[b]{2}{*}{ Items } & \multicolumn{2}{|c|}{ EFA results } & \multicolumn{4}{|c|}{ CFA results } \\
\hline & $\begin{array}{l}\text { Factor } \\
\text { loading }\end{array}$ & $\begin{array}{l}\text { Validity \& } \\
\text { reliability }\end{array}$ & $\begin{array}{l}\text { Factor } \\
\text { loading }\end{array}$ & AVE & $\begin{array}{c}\text { Critical } \\
\text { ratio }\end{array}$ & $\begin{array}{c}\text { Goodness of } \\
\text { fit }\end{array}$ \\
\hline SCC 1 & 0.747 & & 0.636 & & $9.490 * * *$ & \\
\hline $\mathrm{SCC} 2$ & 0.677 & $\mathrm{C}=0.881$ & 0.730 & & $11.075^{* * *}$ & Chi-square \\
\hline SCC 3 & 0.823 & $E=3.848$ & 0.851 & 0.602 & $13.300^{* * *}$ & $=97.538$ \\
\hline $\mathrm{SCC} 4$ & 0.813 & $\% \mathrm{~V}=25.654$ & 0.854 & & $13.425^{* * *}$ & $(\mathrm{p}=0.000)$ \\
\hline SCC 5 & 0.742 & & 0.786 & & - & $\mathrm{df}=56$ \\
\hline SCC 7 & 0.740 & & 0.610 & & $9.553 * * *$ & $\mathrm{Q}=1.742$ \\
\hline SCC 8 & 0.665 & $C=0.866$ & 0.834 & 0628 & $15.087^{* * *}$ & $\mathrm{GFI}=0.939$ \\
\hline SCC 9 & 0.759 & $\begin{aligned} E & =3.006 \\
0 / V & =20037\end{aligned}$ & 0.832 & 0.028 & $15.028 * * *$ & $\mathrm{AGFI}=0.886$ \\
\hline $\mathrm{SCC} 10$ & 0.750 & & 0.868 & & - & $\mathrm{CFI}=0.978$ \\
\hline SCC11 & 0.620 & $\mathrm{C}=0.891$ & 0.695 & & $10.030 * * *$ & RMSEA $=0.0$ \\
\hline $\mathrm{SCC} 12$ & 0.753 & $E=3.717$ & 0.819 & 0.621 & $12.565^{* * *}$ & 60 \\
\hline $\mathrm{SCC} 13$ & 0.842 & $\% \mathrm{~V}=24.780$ & 0.829 & & $12.746^{* * *}$ & \\
\hline
\end{tabular}




\begin{tabular}{c|c|c|c|c|c|c}
\hline \multirow{2}{*}{ Items } & \multicolumn{2}{|c|}{ EFA results } & \multicolumn{4}{c}{ CFA results } \\
\cline { 2 - 6 } & $\begin{array}{c}\text { Factor } \\
\text { loading }\end{array}$ & $\begin{array}{c}\text { Validity \& } \\
\text { reliability }\end{array}$ & $\begin{array}{c}\text { Factor } \\
\text { loading }\end{array}$ & AVE & $\begin{array}{c}\text { Critical } \\
\text { ratio }\end{array}$ & $\begin{array}{c}\text { Goodness of } \\
\text { fit }\end{array}$ \\
\hline SCC14 & 0.828 & & 0.791 & & $11.611^{* * *}$ & \\
SCC15 & 0.816 & & 0.800 & & - & \\
\hline CP 1 & 0.788 & & 0.747 & & $8.648^{* * *}$ & Chi-square \\
CP 2 & 0.858 & $\mathrm{C}=0.886$ & 0.891 & & $9.123^{* * *}$ & $=37.377$ \\
CP 3 & 0.843 & $\mathrm{E}=3.420$ & 0.861 & 0.636 & $9.284^{* * *}$ & $(\mathrm{p}=0.021)$ \\
CP 4 & 0.705 & $\% \mathrm{~V}=34.197$ & 0.733 & & $10.586^{* * *}$ & $\mathrm{df}=22$ \\
CP 5 & 0.669 & & 0.609 & & - & $\mathrm{Q}=1.699$ \\
SP 1 & 0.616 & & 0.642 & & $10.314^{* * *}$ & $\mathrm{GFI}=0.965$ \\
SP 2 & 0.811 & $\mathrm{C}=0.888$ & 0.791 & & $13.792^{* * *}$ & $\mathrm{AGFI}=0.914$ \\
SP 3 & 0.838 & $\mathrm{E}=3.549$ & 0.818 & 0.612 & $14.473^{* * *}$ & $\mathrm{CFI}=0.988$ \\
SP 4 & 0.773 & $\% \mathrm{~V}=35.485$ & 0.779 & & $13.255^{* * *}$ & $\mathrm{RMSEA}=0.0$ \\
SP 5 & 0.858 & & 0.864 & & - & 58 \\
\hline
\end{tabular}

Notes) $* * *: \mathrm{p}<0.01, \mathrm{C}=$ Cronbach's alpha; $\mathrm{E}=$ Eigenvalue; $\% \mathrm{~V}=$ percentage of variance explained; $\mathrm{df}=$ degree of freedom; $Q=$ chi-square/degree of freedom; $\mathrm{GFI}=\mathrm{Good}$ of fit index; $\mathrm{AGFI}=\mathrm{Adjusted}$ GFI: $\mathrm{CFI}=$ Comparativefit index; RMSEA=Root mean square error of approximation

As shown in $<$ Table $2>$, there are no problems in exploratory factor analysis results but SCC 6 is removed because it is included in customer collaboration (factor cross loading). Concerned with SCC, KMO is 0.901 and the result of Bartlett test has no problem (chi-square $=2148.393, \mathrm{df}=105$ and $\mathrm{p}=0.000$ ) and similarly, the result of performance is no problem because the result of Bartlett test shows chi-square $=1344.418, \mathrm{df}=45$ and $\mathrm{p}=0.000$ and $\mathrm{KMO}$ is also 0.866 . The other results also show no problems. For this reason, there is no problem in exploratory factor analysis of collected data. In addition, on the basis of the result of confirmatory factor analysis, there is no problem with collected data. The results of critical ratio are over 1.96 and the AVE and goodness of fit have no problems. This means that the data has convergent validity. Discriminant validity can be tested by comparison of the AVE with squared correlation coefficients.

Table 3.

The Result of Correlation Analysis

\begin{tabular}{c|c|c|c|c|c|c|c}
\hline variables & average & S.D. & CC & SC & IC & CP & SP \\
\hline CC & 4.064 & 1.276 & 1.000 & & & & \\
\hline SC & 3.960 & 1.414 & $\begin{array}{c}0.662^{* * *} \\
(0.438)\end{array}$ & 1.000 & & & \\
\hline IC & 4.009 & 1.289 & $\begin{array}{c}0.521^{* * *} \\
(0.271)\end{array}$ & $\begin{array}{c}0.626^{* * *} \\
(0.392)\end{array}$ & 1.000 & & \\
\hline
\end{tabular}




\begin{tabular}{c|c|c|c|c|c|c|c}
\hline variables & average & S.D. & CC & SC & IC & CP & SP \\
\hline CP & 4.089 & 1.153 & $\begin{array}{c}0.360^{* * *} \\
(0.130)\end{array}$ & $\begin{array}{c}0.293^{* * *} \\
(0.086)\end{array}$ & $\begin{array}{c}0.443^{* * *} \\
(0.196)\end{array}$ & 1.000 & \\
\hline SP & 4.264 & 1.156 & $\begin{array}{c}0.594^{* * *} \\
(0.353)\end{array}$ & $\begin{array}{c}0.592^{* * *} \\
(0.350)\end{array}$ & $\begin{array}{c}0.595^{* * *} \\
(0.354)\end{array}$ & $\begin{array}{c}0.636^{* * *} \\
(0.404)\end{array}$ & 1.000 \\
\hline
\end{tabular}

Notes) ***: $\mathrm{P}<0.01$; $\mathrm{CC}=$ customer collaboration; $\mathrm{SC}=$ supplier collaboration; $\mathrm{IC}=$ internal collaboration; $\mathrm{CP}=$ cost performance; $\mathrm{SP}=$ service performance; S.D.=standard deviation

As shown in $<$ Table $3>$, all squared correlation coefficients are below 0.5 and this means that there is no problem in discriminant validity. In addition, all correlations between variables are significant in $1 \%$ and this has two meanings. One is that independent variables explain dependent variables very well and the other is that multicollinearity is doubted in the relationships between independent variables. For this reason, the variables are tested by multicollinearity. If tolerance is over 0.1 and VIF is below 10.0, there is no problem. The result shows that customer collaboration is 0.543 in tolerance and 1.842 in VIF, supplier collaboration is 0.453 in tolerance and 2.208 in VIF and IC is 0.588 in tolerance and 1.701 in VIF. This means that there is no problem with multicollinearity. Therefore, there are no problems in reliability and validity of collected data.

\subsection{The Results of Hypotheses Test}

To test hypotheses, this research uses SEM. The results are as follows.

\section{Table 4.}

The result of a Causal Link among EC, IC and Performance

\begin{tabular}{c|c|c|c|c|c|c}
\hline H. & Path & Estimate & S.E. & C.R. & P & Result \\
\hline 1a & CC $\rightarrow$ IC & 0.211 & 0.094 & 2.239 & 0.025 & supported \\
\hline lb & SC $\rightarrow$ IC & 0.522 & 0.084 & 6.240 & 0.000 & supported \\
\hline $1 \mathrm{c}$ & $\mathrm{IC} \rightarrow \mathrm{CP}$ & 0.490 & 0.070 & 6.756 & 0.000 & supported \\
\hline $1 \mathrm{~d}$ & $\mathrm{IC} \rightarrow \mathrm{SP}$ & 0.470 & 0.063 & 7.501 & 0.000 & supported \\
\hline
\end{tabular}

Notes) Chi-square $=390.616 ; \mathrm{df}=221 ; \mathrm{p}=0.000 ; \mathrm{Q}=1.767 ; \mathrm{GFI}=0.874 ;$ AGFI $=0.828 ; \mathrm{CFI}=0.950 ; \mathrm{RMSEA}=0.061$

As shown in $<$ Table 4>, customer collaboration and supplier collaboration as EC have a positive effect on IC and it has a positive effect on performance such as cost and service 
(H. 1 is supported). However, goodness of fit is not good; that is, p value on chi-square is supported and GFI and AGFI show below 0.9. This means that the character of the sample firms is not the same as the character of the population and, as a result, the result can be applied to the sample firms.

Table 5.

The Result of a Causal Link among IC, EC and Performance

\begin{tabular}{c|c|c|c|c|c|c}
\hline H. & Path & Estimate & S.E. & C.R. & P & Result \\
\hline $2 \mathrm{a}$ & $\mathrm{IC} \rightarrow \mathrm{CC}$ & 0.576 & 0.079 & 7.282 & 0.000 & supported \\
\hline $2 \mathrm{~b}$ & $\mathrm{IC} \rightarrow \mathrm{SC}$ & 0.941 & 0.090 & 10.434 & 0.000 & supported \\
\hline $2 \mathrm{ac}$ & $\mathrm{CC} \rightarrow \mathrm{CP}$ & 0.319 & 0.079 & 4.030 & 0.000 & supported \\
\hline $2 \mathrm{ad}$ & $\mathrm{CC} \rightarrow \mathrm{SP}$ & 0.228 & 0.049 & 4.670 & 0.000 & supported \\
\hline $2 \mathrm{bc}$ & $\mathrm{SC} \rightarrow \mathrm{CP}$ & 0.125 & 0.056 & 2.215 & 0.027 & supported \\
\hline $2 \mathrm{bd}$ & $\mathrm{SC} \rightarrow \mathrm{SP}$ & 0.235 & 0.039 & 5.967 & 0.000 & supported \\
\hline
\end{tabular}

Notes) Chi-square $=393.967 ; \mathrm{df}=214 ; \mathrm{p}=0.000 ; \mathrm{Q}=1.841 ; \mathrm{GFI}=0.862 ; \mathrm{AGFI}=0.807 ; \mathrm{CFI}=0.947$; RMSEA=0.064

As shown in <Table 5>, IC has a positive effect on EC such as supplier and customer collaboration, which have a positive effect on performance such as cost and service (H. 2 supported). However, goodness of fit is also not good. P value on chi-square is supported and this means that the character of the sample firms is not equal to the character of the population. In addition, GFT and AGFI are not satisfactory in the criteria. The results of the analyses explain that IC has an influence on EC and the reverse is also possible. This is the same result with prior research.

There are two dependent variables such as cost performance and service performance. For this reason, gaps in performance among levels of SCC can be tested by MANOVA. There are two folds for the analysis: the first is to classify four clusters on the basis of SCC such as IC and EC and the second is to ascertain gaps in cost performance and service performance among the four clusters. First of all, clusters are divided on the basis of IC and EC and there are tested as to whether they are different groups from each other. Cluster analysis and ANOVA are used as analytical methods. The result shows that IC has four clusters such as cluster $1(n=62,4.493)$, cluster $2(n=52,2.400)$, cluster $3(n=41,5.629)$ and cluster $4(\mathrm{n}=53,3.766)$ which is $211.030(\mathrm{p}<0.000)$ in F value as a result of AVONA and EC has also four clusters such as cluster 1 (3.430), cluster 2 (2.792), cluster 3 (5.659) and cluster 4 (4.614) which is $188.676(\mathrm{p}<0.000)$ in $\mathrm{F}$ value as a result of ANOVA. On the basis of these results, clusters can be classified as four different levels of SCC such as 
independent operation in each function (Cluster 2 which has low IC and EC), IC (Cluster 1 which has high IC and low EC), EC (Cluster 4 which has high EC and low IC) and SCC (Cluster 3 which has high IC and EC).

MANOVA has preconditions before testing hypotheses such as independence among clusters, equality of error variance, a normal distribution and homoscedasticity. The first is tested by ANOVA as above, and the result shows that they are different clusters. The second is tested by a covariance of matrix among clusters and the result shows that they have equality $(\mathrm{p}=0.224)$. The third is tested by a multivariate test and the result shows that they have a multivariate normal distribution $(\mathrm{P}<0.000)$. The fourth is tested by Levene's test and the result shows that there are no problems in homoscedasticity among clusters (cost performance has 0.783 in $p$ value and service performance has 0.172 in $p$ value). Therefore, the preconditions of MANOVA are satisfactory.

\section{Table 6.}

Tests of Between-Subjects Effects

\begin{tabular}{c|c|c|c|c|c|c}
\hline Source & $\begin{array}{c}\text { Dependent } \\
\text { variables }\end{array}$ & $\begin{array}{c}\text { Type III sum } \\
\text { of squares }\end{array}$ & df & $\begin{array}{c}\text { Mean } \\
\text { square }\end{array}$ & F & p \\
\hline $\begin{array}{c}\text { Corrected } \\
\text { model }\end{array}$ & cost & $52.938 \mathrm{a}$ & 3 & 17.646 & 16.198 & 0.000 \\
\hline \multirow{2}{*}{ Intercept } & service & $107.846 \mathrm{~b}$ & 3 & 35.949 & 43.394 & 0.000 \\
\hline Levels of & service & 3454.505 & 1 & 3454.505 & 3170.994 & 0.000 \\
SCC & cost & 52.938 & 3 & 17.646 & 16.198 & 0.000 \\
\hline \multirow{2}{*}{ Error } & service & 107.846 & 3 & 35.949 & 43.394 & 0.000 \\
\hline \multirow{2}{*}{ Total } & cost & 222.239 & 204 & 1.089 & & - \\
& service & 168.996 & 204 & 0.828 & - & - \\
\hline Corrected & cost & 3753.640 & 208 & - & - & - \\
total & cost & 4057.680 & 208 & - & & - \\
\hline
\end{tabular}

Notes) a: R2 =0.192 (adj R2 =0.180), b: R2 =0.390 (adj R2 =0.381)

The result of testing MANOVA shows gaps in cost performance and service performance among levels of SCC (H. 3 and H. 4 supported). As shown in $\langle$ Table 6$\rangle$, the result shows that cost performance is 16.198 in $F$ value $(p<0.000)$ and service performance is 43.394 in $F$ value $(p<0.000)$. Compared on the basis of $R$ square, service performance is much higher than cost performance. This means that a gap in service performance among levels of SCC is much clearer than a gap in cost performance among levels of SCC. Next is the result of post hoc analysis. 
Table 7.

Cost Performance Improvement among Different Levels of SCC (Scheffe Test)

\begin{tabular}{|c|c|c|c|c|c|}
\hline Cluster & $\mathbf{N}$ & 1 & 2 & 3 & ANOVA (F) \\
\hline 2 & 52 & 3.323 & & & \\
\hline 4 & 53 & & 4.113 & & 16.198 \\
\hline 1 & 62 & & 4.239 & 4.239 & $(\mathrm{p}<0.000)$ \\
\hline 3 & 41 & & & 4.805 & \\
\hline \multicolumn{2}{|c|}{$\mathrm{p}$ value } & 1.000 & 0.947 & 0.061 & - \\
\hline
\end{tabular}

As shown in $<$ Table 7>, H. 3 is supported because the result of ANOVA is supported $(\mathrm{F}=16.198)$. The result of ANOVA shows independence among clusters. If an alternative hypothesis is supported $(\mathrm{p}<0.05)$, they are regarded as different clusters. As shown in $<$ Table $7>$, there are three groups. The first group has Cluster 2 (independent operation). It is 3.323 in cost performance, which has the lowest cost performance. The second group includes Cluster 4 (EC) and Cluster 1 (IC). The former is 4.113 and the latter is 4.239 in cost performance. On the other hand, Cluster 1 is also classified in the third group which has Cluster 3 (SCC). Cluster 3 is 4.805 in cost performance, which is the highest. Cluster 1 is included in the same group with Cluster 3 but Cluster 1 has the closer relationship with Cluster 4 because $p$ value of the second group (0.947) is higher than the one of the third group (0.061). In addition, the result of ANOVA shows that clusters are independent each other $(\mathrm{F}=16.198)$. As a result, $\mathrm{H} .3$ is supported. In addition, $\mathrm{p}$ values of all groups are not supported $(p>0.05)$ and this means that clusters in each group are not independent.

Table 8.

Service Performance Improvement among Different Levels of SCC (Scheffe Test)

\begin{tabular}{c|c|c|c|c|c}
\hline Cluster & $\mathbf{N}$ & $\mathbf{1}$ & $\mathbf{2}$ & $\mathbf{3}$ & ANOVA (F) \\
\hline 2 & 52 & 3.273 & & & \\
1 & 62 & & 4.194 & & 43.394 \\
4 & 53 & & 4.419 & & $(\mathrm{p}<0.000)$ \\
3 & 41 & & & 5.424 & \\
\hline \multicolumn{2}{c|}{$\mathrm{p}$ value } & 1.000 & 0.669 & 1.000 & - \\
\hline
\end{tabular}

As shown in $<$ Table 8>, H. 4 is supported because the result of ANOVA is supported $(\mathrm{F}=43.394)$. There are three groups. The first group has Cluster 2 (independent operation) and it is 3.273 in service performance, which is the lowest. The second group has Cluster 1 (IC) and Cluster 4 (EC). The former is 4.194 and the latter is 4.419 in service performance. 
Cluster 3 (SCC) is 5.424 in service performance which is the highest. In addition, the result of ANOVA shows that clusters are independent from each other. Similarly, as shown in $p$ values of the three groups, the first group includes Cluster $2(p=1.000)$, the second group includes Cluster 4 and Cluster $1(\mathrm{p}=0.669)$ and the third group includes Cluster $3(\mathrm{p}=$ 1.000). This explains that clusters in the second group are not independent from each other.

\subsection{Discussion}

The results can be explained as follows. First, EC and IC have positive effects on each other, which have a positive effect on performance. This means that the efficiency of internal processes is the cause of promoting connection with external processes but, on the other hand, information generated from exterior is the basis of variance of internal processes. This viewpoint can be explained by contingency theory and information processing theory. From the viewpoint of contingency theory, suppliers and customers are treated with environmental factors (Flynn et al., 2010). Firms acquire information through interaction with suppliers and customers as external environment and they build efficient internal processes following the information. In this regard, the role of managers is to mediate the relationship between external information and internal processes. From the viewpoint of information processing theory, managers learn external information and, consequently, external information is disseminated in internal processes. The organizational behavior is the basis of constructing efficient internal processes and efficient internal processes constructed by this method are also the basis of better connecting suppliers and customers. For this reason, IC is the basis of EC (Branuscheidel and Suresh, 2009; Chen et al., 2009; Gimenez, 2006; Schoenherr and Swink, 2012) and EC is also the basis of IC (Bae, 2012; Gimenez and Ventura, 2008; Salvador et al., 2001; Stank et al., 2001). As a result, firms can enjoy high cost saving and service improvement. This perspective is a perspective of a flow of SCC, which is different from the strategic choice perspective. In this regard, the strategic choice perspective on SCC reflects that firms can choose IC, EC or SCC and, as a result, enjoy performance improvement.

Second, the perspective of this research is different with the perspective of prior research concerned with a flow of SCC (Stevens, 1989). Prior research insisted that SCC starts from inter-functional collaboration and developed to EC by way of IC (Chow et al., 1995; Daugherty et al., 1996; Narasimhan and Kim, 2001). However, the perspective of this research is that firms can choose their strategy in different levels of SCC and this is a similar perspective with Flynn et al. (2010), Frohlich and Westbrook (2001), Gimenez (2006), Schoenherr and Swink (2012), Stock et al. (2000) and Thun (2010). On the basis of 
strategic choice theory, firms can choose a strategy on the basis of their recognition of environment. Firms which recognize high environmental uncertainty choose an external-oriented strategy like EC for acquiring information and finding opportunities in external environment and this is the basis of performance improvement. On the other hand, firms which recognize environmental stability focus on internal processes like IC because they cannot find opportunities in external environment and this is the basis of efficiency improvement (Bae, 2011).

Third, this research verifies both the viewpoint of the directions of SCC and the strategic choice viewpoint of SCC to better understand SCC. The results show that both of them are significant. This means that the two viewpoints are not antagonistic relationships but mutual coexisting relationships. In other words, the viewpoint of the directions of SCC explains that firms start from recognition of SCC, perform IC and EC and, finally, achieve SCC and this is the viewpoint of development stages of SCC. The explanation is connected with performance improvement. In addition, SCC in a strategic choice viewpoint explains methods of a corporate strategic choice to enhance performance at the present time. Both of them approach SCC from different viewpoints but they explain the methods for performance improvement after all. Therefore, the two viewpoints can coexist.

Fourth, the improvement of service performance among different levels of SCC is more definite than the improvement of cost performance. There are three reasons. One is R-square of the result of MANOVA as shown in $\langle$ Table 6>. R-square of service performance shows 0.390 ( 0.381 in adj R-square), whereas the one of cost performance represents 0.192 (0.180 in adj R-square). Another is performance improvement among different levels of SCC. The improvement of cost performance is divided into three groups but cluster 1 is included in both the second group and third group, whereas the improvement of service performance, which is also divided into three groups but they are definitely classified. In addition, the highest coefficient of service performance (5.424) is larger than the one of cost performance (4.805). The third is concerned with $\mathrm{F}$ value in the results of performance improvement among different levels of SCC as shown in <Table 7> and $\langle$ Table $8>$. Service performance is 43.394 and cost performance is 16.198 as F value. This means that the improvement of service performance is much clearer than the improvement of cost performance. Therefore, firms can achieve more definite results in service performance when they perform SCC. 


\section{Conclusion}

This research has three objectives: one is to verify the mutual effects between IC and $\mathrm{EC}$, another is to prove performance improvement among different levels of SCC, and the third is to analyze gaps between the two viewpoints. To achieve the objectives, Korean FDI firms in China responded to a questionnaire and collected data was analyzed. There were various analytical methods such as reliability and validity analyses, SEM, cluster analysis, ANOVA, MANOVA and post hoc analysis. Managerial implications, limitations and future research directions on the basis of the results are as follows.

The results have managerial implications as follows. First, managers need to recognize the mutual effect between IC and EC. This means that SCC is achieved by construction of collaborative mind and behavior, followed by high performance (Min et al., 2005). For this reason, managers need to find their position in levels of SCC and if they are in IC or EC, they do not focus on just one but focus on both of them. This means that they should make an effort to achieve SCC. The effort is connected with high performance. Second, managers can grasp their level of present SCC on the basis of the above classification and ascertain improving methods of real performance. For instance, if firms are included in the level of an independent operation, they can increase cost performance and service performance through enhancing IC or EC. In addition, firms which are included in the level of IC or EC can enjoy high cost performance and service performance when they move on the level of SCC. The most important aspect of the levels of SCC is to find a weak point of their level of present SCC. If firms are included in the level of IC, managers should focus on EC and they move on a level of SCC, followed by high performance. Similarly, if firms are included in the level of EC, managers should focus on IC and they move on the level of SCC, followed by high performance. In addition, if firms are included in the level of an independent operation, managers can make strategies to ascertain the present external environment and internal resources of firms, to perform IC or EC to accord with their contexts and to achieve SCC from the long-term viewpoint. To achieve this, managers should generate recognition of staff on SCM and support the activity that innovation (like SCC) takes root in internal firms through absorptive capabilities such as business process reengineering (BPR) and learning. Therefore, the confirmation of firms to a level of SCC at present is the basis of strategic choice of firms for performance improvement.

This research has limitations as follows. First, the data used in this research was collected from Korean FDI firms in China. This is one of the advantages of this research because of verifying a strategic viewpoint of SCM concerned with FDI firms, whereas the survey was performed in 2006 which is a disadvantage. This means that it is possible for 
there to be changes of the character caused by environmental variances in the Chinese market. Second, this research analyzed the effect of IC and EC on performance from the viewpoint of fit as mediation of Venkatraman (1989). However, the two variables can also be analyzed from the viewpoint of fit as moderation of Venkatraman (1989). This means that the two variables have an interactive effect or synergy effect (Boon-itt and Wong, 2011b; Droge et al., 2004; Flynn et al., 2010) and an indirect effect (Droge et al., 2004; Gimenez, 2006; Stank et al., 2001) as well as an independent effect (Schoenherr and Swink, 2012; Stank et al., 2001) on performance. This may be treated with future research directions.

\section{Acknowledgement}

This study was financially supported by the ${ }^{2} 2014$ Post-Doc. Development Progra $\mathrm{m} \bumpeq$ of Pusan National University. 


\section{References}

Bae, H.S.2011.The Relationships between Environment, Integration and Performance in Supply Chain Contexts. The Asian Journal of Shipping and Logistics. 27(1): 61-90.

Bae, H.S. 2012, "An Analysis of Gaps in Performance among Development Stages of Integration in SCM", Journal of International Logistics and Trade, 10(3): pp. 85-104.

Bae, H.S. 2012, "The Influencing Factors of Logistics Integration and Customer Service Performance for Value Creation of Port Logistics Firms", The Asian Journal of Shipping and Logistics, 28(3), 343-366.

Bae, H.S. 2012, "The Interactive Effect of Supply Chain Integration on Performance of International Freight Forwarders", Journal of International Logistics and Trade, 12(2): pp. 97-119.

Bae, H.S. 2014, Investigating the Effect of Environmental Uncertainty on Supply Chain Collaboration and Operational Performance, Ph.D. Dissertation, University of Hull, the UK.

Bagchi, P.K., B.C. Ha, T. Skjoett-Larsen and L.B. Soerensen. 2005. Supply Chain Integration: a European Survey. The International Journal of Logistics Management. 16(2): 275-294.

Barney, J. 1991. Firm Resources and Sustained Competitive Advantage. Journal of Management. 17(1): 99-120.

Boon-itt, S. and C.Y. Wong. 2011a.The Moderating Effects of Technological and Demand Uncertainties on the Relationship between Supply Chain Integration and Customer Delivery Performance. International Journal of Physical Distribution and Logistics Management. 41(3): 253-276.

Boon-itt, S. and C.Y. Wong. 2011b.The Interactions between Internal and External Integration and Their Combined Effects on Operational Performance. POMS $22^{\text {nd }}$ Conference Reno, USA, Paper No. 020-0296.1-20. 
Braunscheidel, M.J. and N.C. Suresh. 2009. The Organizational Antecedents of a Firm's Supply Chain Agility for Risk Mitigation and Response. Journal of Operations Management. 27(2): 119-140.

Brewer, P.C. and T.W. Speh.2000. Using the Balanced Scorecard to Measure Supply Chain Performance. Journal of Business Logistics. 21(1): 75-943.

Buckley, P. and M. Casson.1976.The Future of the Multinational Enterprise. London, Macmillan.

Chen, H., P.J. Daugherty and A.S. Roath. 2009. Defining and Operationalizing Supply Chain Process Integration. Journal of Business Logistics. 30(1): 63-84.

Chow, G., T.D. Heaver and L.E. Henriksson. 1995. Strategy, Structure and Performance: A Framework for Logistics Research. Logistics and Transportation Review. 31(4): 285-308.

Danese, P. and P. Romano. 2011. Supply Chain Integration and Efficiency Performance: A Study on the Interactions between Customer and Supplier Integration. Supply Chain Management: An International Journal. 16(4): 220-230.

Daugherty, P.J., H. Chen, D.D. Mattioda and S.J. Grawe. 2009. Marketing/Logistics Relationships: Influence on Capabilities and Performance. Journal of Business Logistics. 30(1): 1-18.

Daugherty, P.J., A.E. Ellinger, and C.M. Gustin. 1996. Integrated Logistics: Achieving Logistics Performance Improvements. Supply Chain Management: an International Journal. 1(3): 25-33.

Droge, C., J. Jayaram and S.K. Vickery. 2004. The Effects of Internal versus External Integration Practices on Time-based Performance and Overall Firm Performance. Journal of Operations Management. 22: 557-573.

Ellinger, A.E., P.J. Daugherty and S.B. Keller. 2000. The Relationship between Marketing/Logistics Interdepartment Integration and Performance in U.S. Manufacturing Firms: An Empirical Study. Journal of Business Logistics. 21(1): $1-22$. 
Flynn, B.B., B. Huo and X. Zhao. 2010. The Impact of Supply Chain Integration on Performance: A Contingency and Configuration Approach. Journal of Operations Management. 28: 58-71.

Frohlich, M.T. and R. Westbrook. 2001. Arcs of Integration: An International Study of Supply Chain Strategies. Journal of Operations Management. 19: 185-200.

Germain, R. and K.N.S. Iyer. 2006. The Interaction of Internal and Downstream Integration and Its Association with Performance. Journal of Business Logistics. 27(2): 29-51.

Gimenez, C. and E. Ventura. 2005. Logistics-Production, Logistics-Marketing and External integration: Their Impact on Performance. International Journal of Operations and Production Management. 25(1): 231-249.

Gimenez, C. 2006.Logistics Integration Processes in the Food Industry. International Journal of Physical Distribution and Logistics Management. 36(3): 231-249.

Hennart, J. 1982.A Theory of Multinational Enterprise. Ann Arbor. University of Michigan Press.

Iyer, K.N.S. 2011. Demand Chain Collaboration and Operational Performance: Role of IT analytic Capability and Environmental Uncertainty. Journal of Business and Industry Marketing. 26(2): 81-91.

Kahn K.B. and J.T. Mentzer. 1998. Marketing's Integration with other Departments. Journal of Business Research. 42: 53-62.

Kannan, V.R. and K.C. Tan. 2010. Supply Chain Integration Cluster Analysis of the Impact of Span of Integration. Supply Chain Management: An International Journal. 15(3): 207-215.

Kim, S.W. 2006. The Effect of Supply Chain Integration on the Alignment between Corporate Competitive Capability and Supply chain Operational Capability. International Journal of Operations and Production Management. 26(10): 1084-1107. 
Kohli, A.K. and B.J. Jaworski. 1990. Market Orientation: The Construct, Research Propositions, and Managerial Implications. International Journal of Physical Distribution and Logistics Management. 30(10): 847-868.

Korea Export and Import Bank (2011), internal statistics data.

Min, S., A.S.Roath, P.J.Daugherty,S.E.Genchev, H.Chen, D.Arndt, and R.G. Richey. 2005. Supply chain collaboration: what's happening? The International Journal of Logistics Management. 16(2): 237-256.

Mollenkopf, D., A. Gibson and L. Ozanne. 2000. The Integration of Marketing and Logistics Functions: An Empirical Examination of New Zealand Firms. Journal of Business Logistics. 21(2): 89-112.

Morash, E.A. and S.R. Clinton. 1998. Supply Chain Integration: Customer Value through Collaborative Closeness versus Operational Excellence. Journal of Marketing Theory and Practice. 6(4): 104-120.

Narasimhan, R. and S.W. Kim. 2001. Information System Utilization Strategy for Supply Chain Integration. Journal of Business Logistics. 22(2): 51-75.

Narasimhan, R. and S.W. Kim. 2002. Effect of Supply Chain Integration on the Relationship between Diversification and Performance: Evidence from Japanese and Korean Firms. Journal of Operations Management. 20: 303-323.

Nunnally, J.1978.Psychometric Theory, New York: McGrow-Hill.

Rugman, A.M. 1981.Inside the Multinationals, Croom Helm.

Saeed, K.A., M.K. Malhotra and V. Grover. 2011.Interorganizational System Characteristics and Supply Chain Integration: An Empirical Assessment. Decision Sciences. 42(1): 7-41.

Salvador, F., C. Forza, M. Rungtusantham and T.Y. Choi. 2001. Supply Chain Interactions and Time-Related Performances. International Journal of Operations and Production Management. 21(4): 461-475. 
Schoenherr, T and M. Swink. 2012. Revisiting the Arcs of Integration: Cross-Validations and Extensions. Journal of Operations Management. 30: 99-115.

Stank, T.P., S.B. Keller and P.J. Daugherty. 2001. Supply Chain Collaboration and Logistical Service Performance. Journal of Business Logistics. 22(1): 29-48.

Stevens, G.C. 1989.Integrating the Supply Chain. International Journal of Physical Distribution and Logistics Management. 19(8): 3-8.

Stock, G.N., N.P. Greis and J.D. Kasarda. 2000. Enterprise Logistics and Supply Chain Structure: the Role of Fit. Journal of Operations Management. 18: 531-547.

Thun, J.-H. 2010. Angles of Integration: An Empirical Analysis of The Alignment of Internet-based Information Technology and Global Supply Chain Integration. Journal of Supply Chain Management. 46(2): 30-44.

Tuggle, F.D. and D. Gerwin. 1980. An Information Processing Model of Organizational Perception, Strategy and Choice. Management Science. 26(6): 575-592.

Venkatraman, N. 1989.The Concept of Fit in Strategy Research: Toward Verbal and Statistical Correspondence. The Academy of Management Review. 14(3): 423-444. 